\title{
TERT promoter mutation in adult granulosa cell tumor of the ovary
}

\author{
Jessica A. Pilsworth ${ }^{1,2}$ - Dawn R. Cochrane ${ }^{2}$ Zhouchunyang Xia ${ }^{2,3} \cdot$ Geraldine Aubert $^{4}$ • Anniina E. M. Färkkilä5,6 • \\ Hugo M. Horlings ${ }^{2,3} \cdot$ Satoshi Yanagida ${ }^{7}$ Winnie Yang ${ }^{2}$. Jamie L. P. Lim $^{2} \cdot$ Yi Kan Wang $^{2} \cdot$ Ali Bashashati $^{2}$. \\ Jacqueline Keul ${ }^{8} \cdot$ Adele Wong $^{9} \cdot K_{\text {Kevin Norris }}{ }^{10} \cdot$ Sara Y. Brucker $^{8} \cdot$ Florin-Andrei Taran $^{8} \cdot$ Bernhard Krämer $^{8}$. \\ Annette Staebler ${ }^{11}$. Hannah van Meurs ${ }^{12}$ - Esther Oliva $^{9}$. Sohrab P. Shah $\mathbb{1}^{2,13}$. Stefan Kommoss ${ }^{8}$. \\ Friedrich Kommoss $^{14}$ - C. Blake Gilks ${ }^{3}$ Duncan M. Baird ${ }^{10} \cdot$ David G. Huntsman $^{2,3}$
}

Received: 1 October 2017 / Revised: 28 November 2017 / Accepted: 3 December 2017 / Published online: 15 February 2018

(c) United States \& Canadian Academy of Pathology 2018

\begin{abstract}
The telomerase reverse transcriptase (TERT) gene is highly expressed in stem cells and silenced upon differentiation. Cancer cells can attain immortality by activating TERT to maintain telomere length and telomerase activity, which is a crucial step of tumorigenesis. Two somatic mutations in the TERT promoter (C228T; C250T) have been identified as gain-of-function mutations that promote transcriptional activation of TERT in multiple cancers, such as melanoma and glioblastoma. A recent study investigating TERT promoter mutations in ovarian carcinomas found $\mathrm{C} 228 \mathrm{~T}$ and $\mathrm{C} 250 \mathrm{~T}$ mutations in $15.9 \%$ of clear cell carcinomas. However, it is unknown whether these mutations are frequent in other ovarian cancer subtypes, in particular, sex cordstromal tumors including adult granulosa cell tumors. We performed whole-genome sequencing on ten adult granulosa cell tumors with matched normal blood and identified a TERT C228T promoter mutation in 50\% of tumors. We found that adult granulosa cell tumors with mutated TERT promoter have increased expression of TERT mRNA and exhibited significantly longer telomeres compared to those with wild-type TERT promoter. Extension cohort analysis using allelic discrimination revealed the TERT C228T mutation in 51 of 229 primary adult granulosa cell tumors (22\%), 24 of 58 recurrent adult granulosa cell tumors (41\%), and 1 of 22 other sex cord-stromal tumors (5\%). There was a significant difference in overall survival between patients with TERT C228T promoter mutation in the primary tumors and those without it ( $p=0.00253$, log-rank test). In seven adult granulosa cell tumors, we found the TERT C228T mutation present in recurrent tumors and absent in the corresponding primary tumor. Our data suggest that TERT C228T promoter mutations may have an important role in progression of adult granulosa cell tumors.
\end{abstract}

Telomeres are conserved, repetitive (TTAGGG) DNAprotein complexes that are added to the ends of chromosomes by the enzyme telomerase to prevent DNA damage and maintain replicative potential [1]. Telomere attrition during DNA replication induces genomic instability that can result in tumorigenesis [2]. Telomerase consists of a catalytic protein subunit known as telomerase reverse transcriptase (TERT) and a functional RNA called telomerase RNA component (TERC) [3]. $T E R T$ is highly expressed in stem cells and is silenced upon differentiation in somatic cells [4]. Most cancer

Electronic supplementary material The online version of this article (https://doi.org/10.1038/s41379-018-0007-9) contains supplementary material, which is available to authorized users.

David G. Huntsman

dhuntsma@bccancer.bc.ca

Extended author information available on the last page of the article cells attain proliferative immortality by upregulating the TERT gene to maintain telomere length and telomerase activity [5]. The known mechanisms of telomerase activation include mutations in the TERT promoter, TERT gene amplification, $\mathrm{CpG}$ methylation at the TERT promoter, changes in alternative splicing of TERT premRNA and upregulation of transcriptional activators [6]. Approximately $90 \%$ of cancers express TERT, while the remaining $10-15 \%$ of cancers maintain their telomere length through a telomerase-independent method called alternative lengthening of telomeres [7].

TERT promoter mutations were first reported in familial melanoma and subsequently in sporadic melanoma $[8,9]$. There are two hot-spot TERT promoter mutations, C228T and C250T, each generates an identical 11 base-pair sequence containing a consensus binding motif for ETS transcription factors, and functions as either a transcriptional activator or repressor to regulate telomerase expression $[8,9]$. These two mutations are implicated in 
the activation of telomerase in other malignancies such as central nervous system tumors, hepatocellular carcinomas, bladder cancers, and thyroid cancers [10, 11]. A recent study on TERT promoter mutations in gynecological malignancies, including ovarian and uterine carcinomas, reported TERT hot-spot mutations in $15.9 \%$ of ovarian clear cell carcinomas [12]. However, it is unknown whether TERT promoter mutations are frequent in sex cordstromal tumors, including adult granulosa cell tumors. In this study, we evaluated the biological and clinical significance of TERT promoter mutations, specifically C228T, in total of 251 primary ovarian sex cord-stromal tumors.

\section{Materials and methods}

\section{Patient cohort description}

Adult granulosa cell tumors $(n=303)$ were collected from Helsinki University Hospital (Helsinki, Finland; $n=142$ ), Tübingen University Hospital (Tübingen, Germany; $n=49$ ), Massachusetts General Hospital (Boston, USA; $n=41$ ), Netherlands Cancer Institute (Amsterdam, Netherlands; $n=30$ ), OvCaRe Gynecological Tumor Bank, (Vancouver, Canada; $n=20$ ), the Jikei University School of Medicine (Tokyo, Japan; $n=14$ ), and Referral Center for Gynecopathology (Mannheim, Germany; $n=7)$. The other sex cord-stromal tumors were collected from Vancouver General Hospital (Vancouver, Canada; $n=22$ ). The respective institutional research ethics board approved the waiver for patient consent. The British Columbia Cancer Agency and the University of British Columbia Research Ethics Boards approved the overall project methods. All cases were reviewed by at least one of the following expert pathologists (CBG, FK, $\mathrm{HMH}, \mathrm{ANK}, \mathrm{RB}, \mathrm{HL}-\mathrm{C}, \mathrm{BTC}$, and $\mathrm{LH})$ to confirm the diagnosis of the sex cord-stromal tumor. A FOXL2 C402G allelic discrimination assay was used to validate adult granulosa cell tumor diagnosis. Of the 229 primary adult granulosa cell tumors, 223 harbored a heterozygous FOXL2 C402G mutation and 6 harbored a homozygous, and were considered molecularly defined adult granulosa cell tumor as previously described [13]. For the adult granulosa cell tumor sequencing cohort, tumors were reviewed from frozen material, by at least two expert gynecological pathologists (HMH, ANK, HL-C, and $\mathrm{CBG}$ ), and $\mathrm{CBG}$ approved the final selected cohort. All adult granulosa cell tumors sequenced were primary tumor samples. Each respective institution for Helsinki, Boston, Tübingen, Amsterdam, Mannheim, and Tokyo cases collected clinical follow-up data.

\section{Whole-genome sequencing analysis of adult granulosa cell tumors}

A total of ten fresh-frozen adult granulosa cell tumor tissues with $>80 \%$ tumor cellularity (based on frozen hematoxylin and eosin slide review) were selected for cryosectioning and DNA extraction. Patient tumor and normal blood samples were collected at diagnosis during standard-of-care debulking surgery. DNA was extracted from matched normal (peripheral blood buffy coat) and tumor (frozen tissue) samples using QIAmp Blood and Tissue DNA (Qiagen, Mississauga, ON) and quantified using the Qubit Fluorometer with the dsDNA High Sensitivity Assay Kit (ThermoFisher Scientific, Canada). Wholegenome sequencing was performed using Illumina HiSeq 2500 v4 chemistry (Illumina Inc., Hayward, CA) with the PCR-free protocol to eliminate PCR-induced bias and improve coverage across the genome. Whole-genome sequencing analysis was performed to identify somatic alterations in each case, including single-nucleotide variants, small indels, copy number alterations, and structural variants. For a full description of library construction and sequencing methods, please refer to Wang et al. [14].

\section{Direct sequencing of TERT promoter in adult granulosa cell tumors}

TERT promoter (including positions 228 and 250) was PCR amplified from DNA extracted from all ten adult granulosa cell tumors and the recurrent adult granulosa cell tumorderived KGN cell line using the following primers: 5'-CAGCGCTGCCTGAAACTC-3' (forward) and 5'-GTC CTGCCCCTTCACCTT-3' (reverse). DNA was denatured at $94{ }^{\circ} \mathrm{C}$ for $2 \mathrm{~min}$, then DNA was amplified over 35 cycles $\left(94{ }^{\circ} \mathrm{C}\right.$ for $30 \mathrm{~s}, 62^{\circ} \mathrm{C}$ for $30 \mathrm{~s}, 68^{\circ} \mathrm{C}$ for $30 \mathrm{~s}$ ), followed by a final extension at $68^{\circ} \mathrm{C}$ for $5 \mathrm{~min}$ using an MJ Research Tetrad (Ramsey, MN). PCR products were bi-directionally sequenced using an ABI BigDye terminator v3.1 cycle sequencing kit (Applied Biosystems, Foster City, CA) and an ABI Prism 3100 Genetic Analyzer (Applied Biosystems, Foster City, CA).

\section{Screening TERT C228T promoter mutation in extension cohort}

Allelic discrimination for TERT C228T promoter mutation in 229 primary adult granulosa cell tumors, 58 recurrent adult granulosa cell tumors and 22 other sex cord-stromal tumors was determined using a Custom TaqMan SNP Genotyping assay (Applied Biosystems, Foster City, CA). The sequences of the primers were as follows: 5'-CTGCCCCTTCACCTTCCA-3' (forward) and 5'-GGG 
CCGCGGAAAGGAA-3' (reverse). The wild-type-specific probe (5'-VIC dye-CCCAGCCCCCTCCGG-NFQ (nonfluorescent quencher)) and mutant-specific probe (5'-FAM dye-CCAGCCCCTTCCGG-NFQ) were included in the TaqMan Genotyping Master Mix $(2 \times)$ and reactions were performed in the QuantStudio 6 Flex Real-Time PCR System (Applied Biosystems, Foster City, CA) using 20 ng of DNA. After denaturation at $95^{\circ} \mathrm{C}$ for $10 \mathrm{~min}$, DNA was amplified over 50 cycles $\left(95^{\circ} \mathrm{C}\right.$ for $15 \mathrm{~s}, 60^{\circ} \mathrm{C}$ for $90 \mathrm{~s}$ ).

\section{TERT mRNA expression quantification in adult granulosa cell tumors}

RNA was extracted using the miRNAeasy tissue kit (Qiagen, Mississauga, ON) and quantified using the NanoDrop ND1000 Fluorospectrometer (ThermoFisher Scientific, Canada). cDNA synthesis was performed using the SuperScript IV First-Strand Synthesis System on total RNA with $50 \mu \mathrm{M}$ random hexamers (Invitrogen, Carlsbad, CA). TERT mRNA transcript expression was determined from the cDNA by real-time PCR in the QuantStudio 6 Flex RealTime PCR System using the TERT TaqMan probe spanning exons 3 and 4 (Hs00972650_m1) with TaqMan Fast Advanced Master Mix (2×). The 18S (Hs03928990_g1) housekeeping gene was used for normalization (Applied Biosystems, Foster City, CA). The relative levels were calculated using the $\Delta \Delta \mathrm{CT}$ method [15].

\section{Telomere length evaluation in adult granulosa cell tumors}

Telomere length was determined using XpYp single telomere length analysis (STELA) as previously described [16, 17]. Briefly, extracted DNA from all ten adult granulosa cell tumors was quantified by Hoechst 33258 fluorometry (Bio-Rad, Hercules, CA, USA) before dilution to $10 \mathrm{ng} / \mu \mathrm{l}$ in $10 \mathrm{mmol} / \mathrm{l}$ Tris- $\mathrm{HCl}, \mathrm{pH} \mathrm{7.5}$. A total of $10 \mathrm{ng}$ of DNA was further diluted to $250 \mathrm{pg} / \mu \mathrm{l}$ in a volume of $40 \mu \mathrm{l}$ containing $1 \mu \mathrm{mol} / \mathrm{l}$ Telorette2 linker and $1 \mathrm{mmol} / \mathrm{l}$ Tris- $\mathrm{HCl}$, $\mathrm{pH}$ 7.5. Multiple polymerase chain reactions (PCRs; typically 6 reactions per sample) were carried out for each test DNA in $10-\mu 1$ volume with $250 \mathrm{pg}$ of DNA, $0.5 \mu \mathrm{mol} / 1$ of the telomere-adjacent and Teltail primers, $75 \mathrm{mmol} / \mathrm{l}$ Tris$\mathrm{HCl}, \mathrm{pH} 8.8,20 \mathrm{mmol} / \mathrm{l}\left(\mathrm{NH}_{4}\right)_{2} \mathrm{SO}_{4}, 0.01 \%$ Tween-20, $1.5 \mathrm{mmol} / \mathrm{l} \mathrm{MgCl}_{2}$, and 0.5 units of a $10: 1$ mixture of Taq (ABGene, Thermo Scientific) and Pwo polymerase (Roche Molecular Biochemicals, Burgess Hill, West Sussex, UK). The reactions were cycled with an MJ PTC225 thermocycler (MJ Research, Bio-Rad). The DNA fragments were resolved by $0.5 \%$ Tris acetate EDTA agarose gel electrophoresis, and detected by Southern blot hybridization with random-primed $\alpha-33 \mathrm{P}-$ labeled (Perkin Elmer, Waltham, Massachusetts, USA) TTAGGG repeat probe together with probes to detect the 1-kb (Stratagene, Agilent Technologies, Santa Clara, CA, USA) and 2.5-kb (Bio-Rad) molecular weight markers. The hybridized fragments were detected by phosphorimaging with a Typhoon FLA 9500 phosphorimager (GE Healthcare). The molecular weights of the DNA fragments were calculated using the Phoretix 1D quantifier (Nonlinear Dynamics, Newcastle upon Tyne, UK).

\section{Statistical analysis}

Two-tailed Fisher exact tests were performed to compare the frequencies of TERT C228T mutation in adult granulosa cell tumors and other sex cord-stromal tumors, and in primary versus recurrent adult granulosa cell tumors. The frequency of C228T mutation in adult granulosa cell tumors collected from different institutions was evaluated using a two-tailed Fisher's exact test. The TERT mRNA expression levels and telomere lengths of TERT mutant and TERT wild-type tumors were compared using a Mann-Whitney $U$ test to determine whether TERT C228T promoter mutation was associated with increased TERT mRNA expression and longer telomeres, respectively. Overall survival, disease-specific survival and disease-free survival of adult granulosa cell tumors with and without TERT C228T promoter mutation were compared using the Kaplan-Meier method, followed by the log-rank test to determine significance.

\section{Results}

\section{TERT C228T promoter mutation is frequent in adult granulosa cell tumors}

Whole-genome sequencing analysis was performed on ten adult granulosa cell tumors and identified a TERT C228T mutation in $50 \%$ of tumors (Fig. 1a). We previously performed whole-genome sequencing analysis on ovarian surface epithelial, including clear cell ovarian carcinomas, endometrioid ovarian carcinomas, and high-grade serous ovarian carcinomas. The frequency of TERT promoter mutations is summarized in Table 1. We found TERT promoter mutations in 2 of 35 clear cell ovarian carcinomas (5.7\%), 1 of 29 endometrioid ovarian carcinomas $(3.4 \%)$ and 0 of 59 high-grade serous ovarian carcinomas $(0 \%)$ [14]. We did not identify any TERT C250T promoter mutations in adult granulosa cell tumors, thus our allelic discrimination analysis was performed for TERT C228T mutation in the extension cohort. The frequency of TERT $\mathrm{C} 228 \mathrm{~T}$ promoter mutation in the extension cohort of adult granulosa cell tumors and other sex cord-stromal tumors is summarized in Table 2. The C228T change was detected in 
a
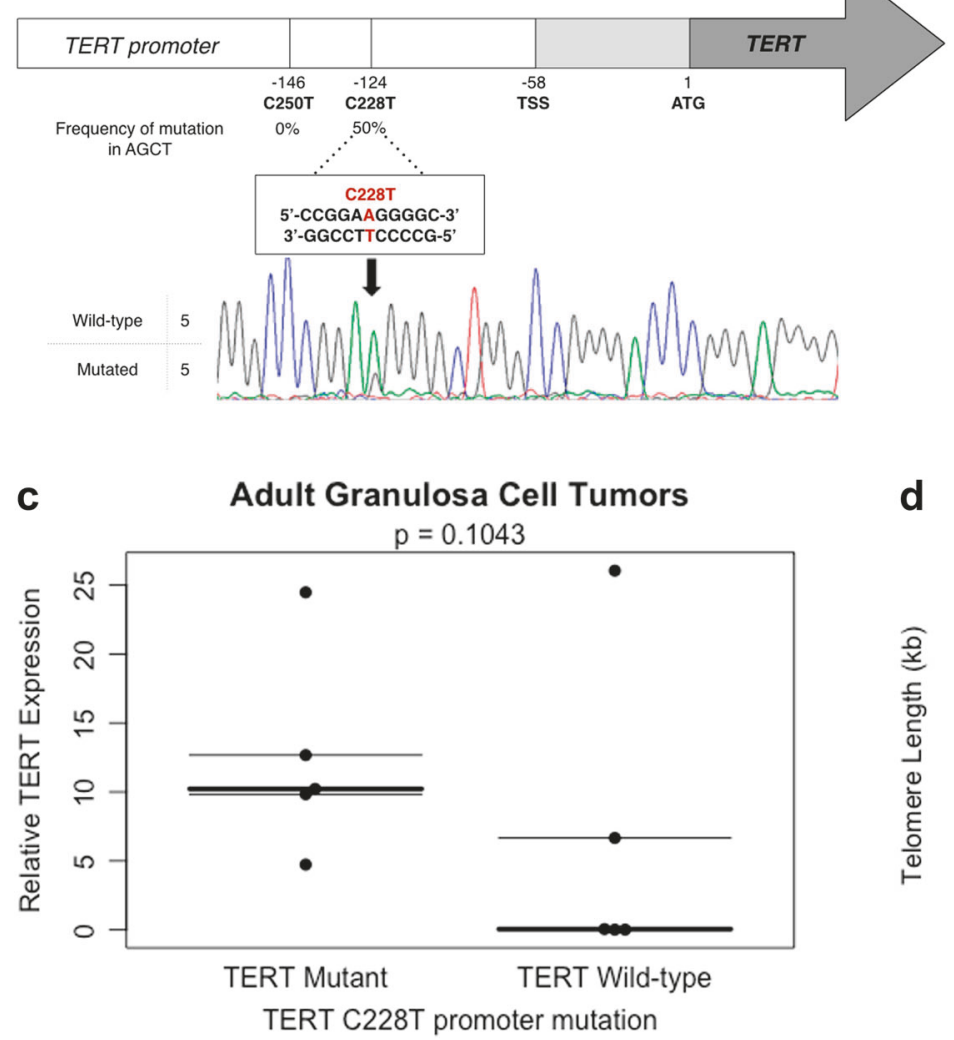

Fig. 1 a TERT promoter mutation in adult granulosa cell tumors. Shown is the schematic diagram of the TERT promoter region, representative chromatograms of the two hot-spot mutations (C228T; C250T). b Mutation status of TERT C228T promoter in adult granulosa cell tumors separated by the country in which they were collected from: dark gray, TERT C228T mutated promoter; light gray, TERT

52 of 251 primary tumor samples (21\%), with the majority occurring in adult granulosa cell tumors. The mutation was present in 51 of 229 primary adult granulosa cell tumors (22\%) and 24 of 58 recurrent adult granulosa cell tumors (41\%), while only in 1 of 22 other sex cord-stromal tumors (5\%). The mutation frequency between primary adult granulosa cell tumors and other sex cord-stromal tumors was not significant ( $p=0.05448$, two-tailed Fisher's exact test). The C228T mutation was also present in the KGN cell line, which was derived from a patient with a recurrent adult granulosa cell tumor. There was no significant difference in TERT C228T mutation frequency among adult granulosa cell tumors collected from different countries $(p=0.5843$, two-tailed Fisher's exact test, Fig. 1b).

\section{TERT C228T promoter mutation is associated with elevated mRNA expression in adult granulosa cell tumors}

Among the ten adult granulosa cell tumors, we found that the five cases with a TERT C228T mutation showed a
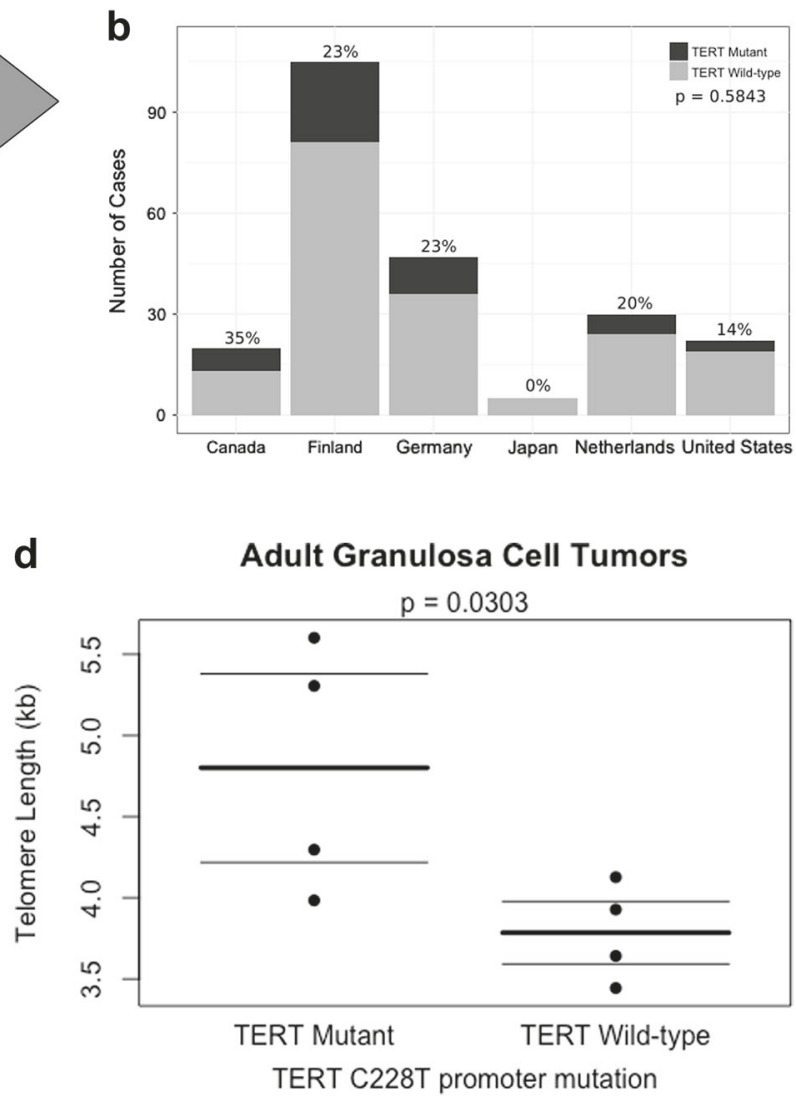

wild-type promoter. c Adult granulosa cell tumors with mutated TERT promoter have increased expression of TERT mRNA; black horizontal bar, mean. d Comparison of XpYp STELA telomere length mean between adult granulosa cell tumors with and without TERT promoter mutation; black horizontal bar, group mean

Table 1 Prevalence of TERT C228T and C250T promoter mutations in ovarian cancer

$\begin{array}{lll}\text { C228T C250T } & \begin{array}{l}\text { Mutated } \\ \text { Total }\end{array}\end{array}$

Ovarian cancer

$\begin{array}{llll}\text { Adult granulosa cell tumor } & 5 & 0 & 5 / 10\end{array}$

$\begin{array}{lllll}\text { Clear cell ovarian carcinoma } & 1 & 1 & 2 / 35 & 5.7\end{array}$

$\begin{array}{lllll}\text { Endometrioid ovarian } & 1 & 0 & 1 / 29 & 3.4\end{array}$

carcinoma

$\begin{array}{lllll}\text { High-grade serous ovarian } & 0 & 0 & 0 / 59 & 0\end{array}$

carcinoma

10.8-fold increase of TERT mRNA expression as compared to the five tumors without a TERT promoter mutation. The majority of adult granulosa cell tumors harboring a TERT C228T mutation expressed higher levels of TERT mRNA compared to those with a wild-type TERT promoter (Fig. 1c). However, the difference was not significant ( $p=0.1043$, Mann-Whitney $U$ test). Interestingly, 
Table 2 Prevalence of TERT C228T promoter mutation in ovarian sex cord-stromal tumors

\begin{tabular}{lll}
\hline & Mutated/total & $\%$ \\
\hline Ovarian sex cord-stromal tumor & & \\
Primary adult granulosa cell tumor & $51 / 229$ & 22 \\
Recurrent adult granulosa cell tumor & $24 / 58$ & 41 \\
Adult granulosa cell tumor KGN cell line & $1 / 1$ & 100 \\
Sertoli-Leydig cell tumor & $1 / 5$ & 20 \\
Fibroma/Thecoma & $0 / 14$ & 0 \\
Gynandroblastoma & $0 / 1$ & 0 \\
Unclassified & $0 / 2$ & 0 \\
\hline
\end{tabular}

we found one wild-type TERT adult granulosa cell tumor expressed a high level of TERT mRNA due to a copy number gain $(n=3)$. When this wild-type TERT adult granulosa cell tumor was removed from the group, TERT promoter mutants expressed significantly higher levels of TERT mRNA compared to those with TERT wild-type promoter $(p=0.01587$, Mann-Whitney $U$ test). We excluded this wild-type TERT adult granulosa cell tumor with the TERT copy number gain (VOA1405b) from subsequent analysis.

\section{Adult granulosa cell tumors with TERT C228T promoter mutation tend to have longer telomeres}

To evaluate the relationship between TERT C228T promoter mutation and telomere length, we assessed the XpYp telomere length in ten adult granulosa cell tumors (Fig. 1d). Some of the tumors exhibited more heterogeneous telomere length distributions, for example VOA985c, VOA1173b, VOA1405b, and VOA1744b (Supplementary Figure 1A-B). Other tumors exhibited more homogenous telomere length distributions along with longer telomeres (Supplementary Figure 1A-B). TERT C228T promoter mutant adult granulosa cell tumors had significantly longer telomeres compared to those with wild-type TERT promoter $(p=0.0303$, Mann-Whitney $U$ test). Three of four tumors (VOA1617a; VOA3082b; VOA4047b) with a TERT mutation yield homogenous telomere length profiles that are typical of clonal growth as seen in the HT1080 Clone 2 control cell line and is most likely mediated by telomerase (Supplementary Figure 1A). The TERT promoter wild-type tumors (VOA985c; VOA1405b) that express TERT mRNA exhibit a wide distribution of telomere lengths and is similar to what has been previously described in alternative lengthening of telomeres cell lines, which use a recombination telomere maintenance process independent of telomerase (Supplementary Figure 1B). Two of the remaining three adult granulosa cell tumors with no TERT mRNA expression yield heterogeneous telomere lengths and resemble tumors that use the alternative lengthening of telomeres process. However, we interrogated the wholegenome sequencing data and did not find any mutations in $A T R X$ or $D A X X$, the two commonly mutated genes described in tumors using the alternative lengthening of telomeres method [18, 19].

\section{TERT C228T promoter mutation is present in recurrent adult granulosa cell tumors but absent in corresponding primary tumors}

Despite the numerous studies on telomerase and TERT expression in multiple cancers, it is poorly defined at which stage telomerase is activated in tumorigenesis. Recent reports identified TERT promoter mutations in early stages of melanoma [20], precursor lesions of hepatocellular carcinomas [21], and benign urothelial lesions [22], suggesting that TERT promoter mutation is an early genetic event in oncogenesis. To determine whether TERT C228T promoter mutation is an early mutation event in adult granulosa cell tumors, we compared the frequency of C228T mutation in primary $(22 \%)$ and recurrent $(41 \%)$ tumors and found the difference to be significant $(p=0.003334$, two-tailed Fisher's exact test, Fig. 2a). We found seven adult granulosa cell tumors with no TERT C228T mutation in the primary tumor but with the mutation in either the first or second recurrent tumor (Fig. 2b). The remaining five adult granulosa cell tumors with primary and recurrent pairs were TERT promoter wild type.

\section{Adult granulosa cell tumor patients with TERT C228T promoter mutation tend to have worse survival}

In 186 primary adult granulosa cell tumor patients with available follow-up data, there was a significant difference in overall survival between patients with TERT C228T promoter mutation and those with TERT wild-type promoter $(p=0.00253$, log-rank test, Fig. 3a). There was no significant difference in disease-specific survival $(p=0.0754$, log-rank test, Fig. 3b) or disease-free survival $(p=0.705$, $\log$ rank test, Fig. 3c).

\section{Discussion}

In this study, we found that adult granulosa cell tumors have the highest frequency of TERT C228T promoter mutation among tumors that have been studied in the ovary including surface epithelial carcinomas and sex cord-stromal tumors. Adult granulosa cell tumors account for $\sim 90 \%$ of sex cordstromal tumors and are characterized by their slow, indolent 

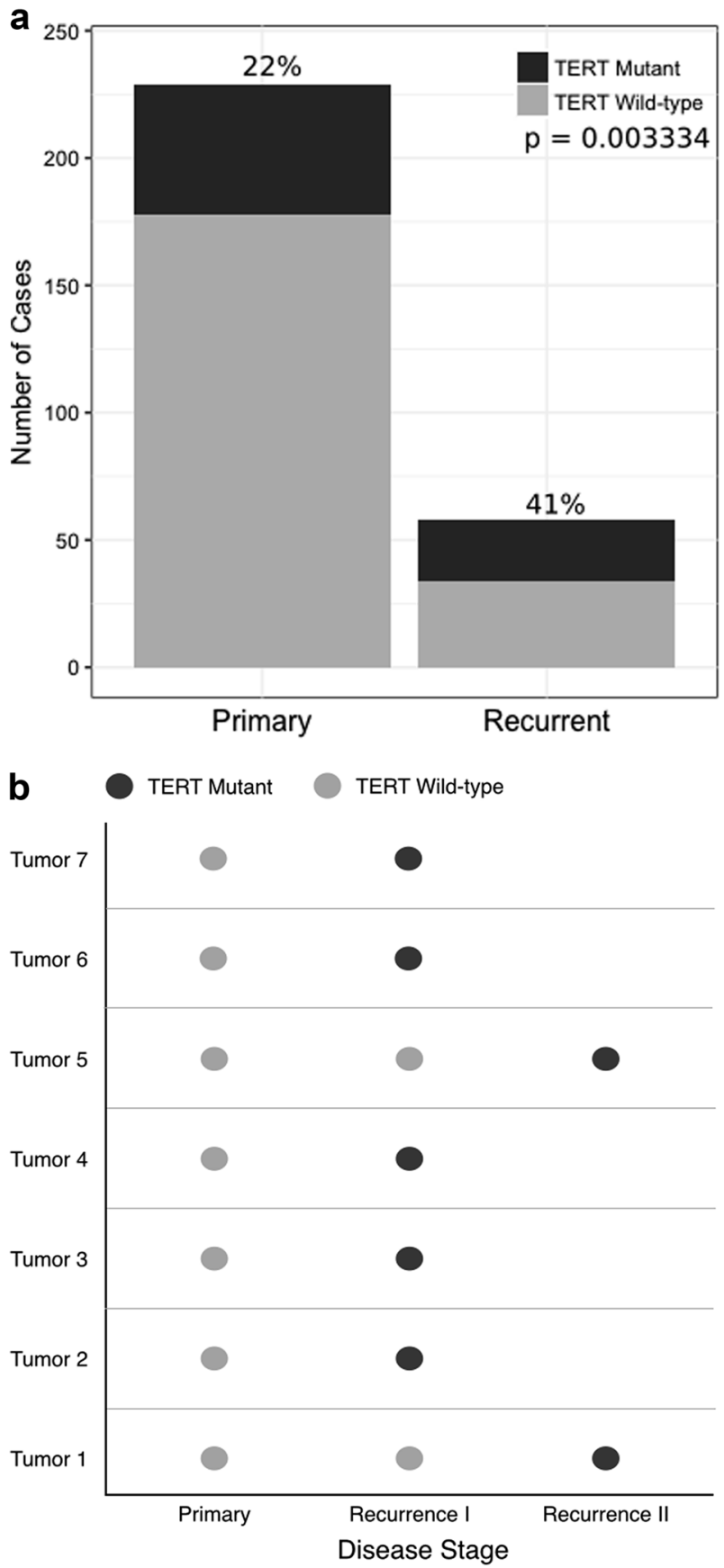

Fig. 2 a Mutation status of TERT C228T promoter in primary and recurrent adult granulosa cell tumors: dark gray, TERT C228T mutated promoter; light gray, TERT wild-type promoter. b An example of acquired TERT C228T promoter mutations in seven adult granulosa cell tumors with primary and recurrent tumor pairs: dark gray, TERT C228T mutated promoter; light gray, TERT wild-type promoter

growth [23]. They are thought to arise from proliferating granulosa cells of the pre-ovulatory stage, as the share several morphological and hormonal features, including estrogen and inhibin synthesis [24]. A single somatic missense mutation in FOXL2 (c.402C > G; pC134W) identified by Shah et al. [25] was reported to be present in 86 of 89 a

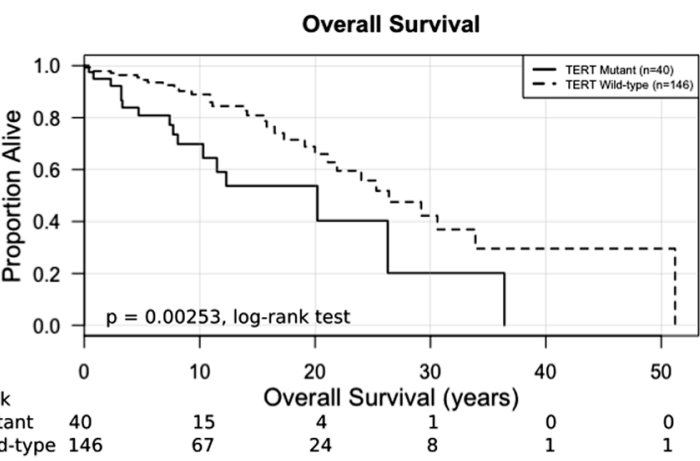

b

Disease-Specific Survival

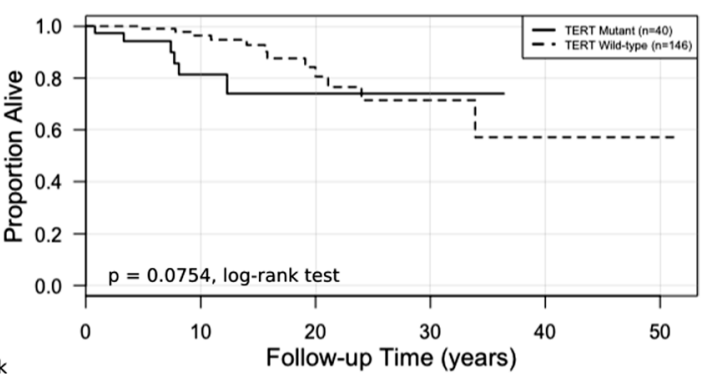

No. at risk

$\begin{array}{lllclll}\text { TERT Mutant } & 43 & 16 & 4 & 1 & 0 & 0 \\ \text { TERT Wild-type } & 135 & 67 & 23 & 7 & 1 & 1\end{array}$

C

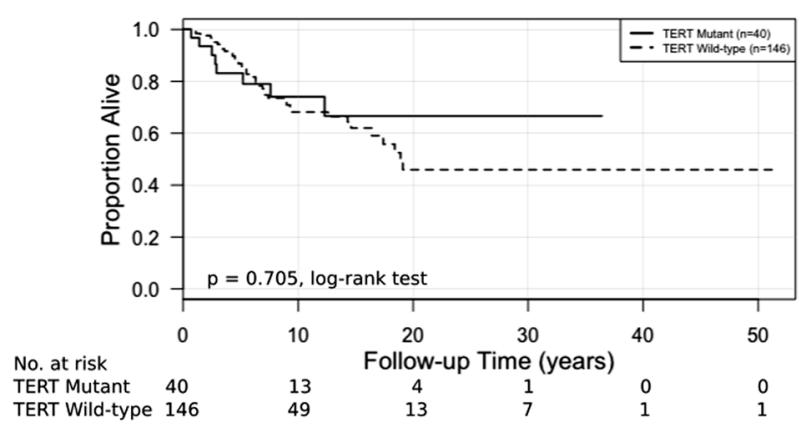

Fig. 3 Kaplan-Meier survival curves of adult granulosa cell tumor patients. a Overall survival in patients with TERT C228T promoter mutation is worse than patients with wild-type TERT promoter ( $p=$ 0.00253 , log-rank test). b Disease-specific survival in patients with TERT C228T promoter mutation is similar to patients with wild-type TERT promoter ( $p=0.0754, \log$-rank test). c Disease-free survival in patients with TERT C228T promoter mutation is similar to patients with wild-type $T E R T$ promoter ( $p=0.705, \log$-rank test)

morphologically defined adult granulosa cell tumors (97\%). Subsequent validation analysis from independent research groups reported the high frequency and specificity of FOXL2 C402G mutation for adult granulosa cell tumors [26-28]. This mutation was also found in small number of other malignant ovarian sex cord-stromal tumors, but not in benign ovarian sex cord-stromal tumors, ovarian surface epithelial tumors or unrelated tumors $[25,29,30]$. This suggests FOXL2 C402G is pathognomonic of adult granulosa cell tumors and can aid in resolving diagnosis for histologically challenging cases [31]. FOXL2 is a member 
of the forkhead box family of transcription factors and plays a fundamental role in ovarian folliculogenesis [32]. The majority of adult granulosa cell tumors are diagnosed at Stage I and therefore cured with surgery. However, late tumor recurrence is common and over $80 \%$ of patients with advanced-stage or recurrent tumors succumb to their disease [33]. As the FOXL2 C402G mutation is present in essentially all adult granulosa cell tumors, it is likely that additional mutations drive tumor progression [25]. Our study is the first to use whole-genome sequencing to provide a comprehensive catalog of coding and non-coding genetic events in adult granulosa cell tumors, the most common among all sex cord-stromal tumors of the ovary. We compared the genomes of ten adult granulosa cell tumors with their matched normal genomes with the objective to identify recurrent mutations that will aid in understanding and improving prognosis. The high frequency of TERT C228T promoter mutation in recurrent adult granulosa cell tumors compared to primary adult granulosa cell tumors highlights a potential mechanism for clonal expansion and recurrence.

Several studies have shown the two hot-spot TERT promoter mutations (C228T; C250T) generate a binding motif for ETS transcription factors and increase transcriptional activity of the TERT promoter [11]. Similarly, we observed higher TERT mRNA expression in adult granulosa cell tumors harboring a TERT C228T promoter mutation, and TERT mutated tumors had significantly longer telomeres compared to TERT wild-type tumors. One TERT wild-type promoter adult granulosa cell tumor with an identified copy number gain expressed high levels of TERT. This result highlights the importance of determining both the genotype and gene expression to identify copy number gains or epigenetic regulation. During ovarian follicle development, telomerase activity is tightly regulated in a temporal and spatial pattern, where TERT expression is dependent on cell type and folliculogenesis stage [34]. Studies have reported that TERT expression correlates with the length of telomeres in primary granulosa cells and that small pre-ovulatory follicles have the highest telomerase activity with the longest telomeres [35]. As the granulosa cells undergo differentiation into luteinized granulosa cells and the follicle develops into the corpus luteum, there is a large decline in telomerase activity [36, 37]. This suggests that telomerase plays an essential role in granulosa cell apoptosis and follicular atresia [36, 38]. Thus, persistent telomerase expression in granulosa cells would result in continued survival beyond the necessary cell divisions and could lead to the development of an adult granulosa cell tumor. Our findings are consistent with a revised model recently proposed by Chiba et al. [39] whereby cells harboring activating TERT promoter mutations extend their proliferative capacity. Our results highlight the importance of telomerase activity in tumor development, where TERT mRNA expression is seen in seven of ten cases, five of which harbor the TERT C228T promoter mutation.

Allelic discrimination analysis of primary and recurrent adult granulosa cell tumors indicates that TERT C228T promoter mutation are already present in some primary tumors, but may be late events which occur during adult granulosa cell tumor progression. Studies have reported TERT promoter mutations as an early genetic event in malignant transformation of multiple cancers [20-22]. In contrast, we found that TERT C228T mutations were present in a significantly higher proportion of recurrent compared to primary adult granulosa cell tumors. We observed TERT mutations in recurrent tumors where no mutations were detected in the corresponding primary tumor (Fig. 2b), suggesting that TERT promoter mutations were acquired during their progression. However, it may also be possible that TERT C228T mutation was present in the primary tumors at a very low frequency that was undetectable. This discordance of TERT mutation in paired primary and recurrent adult granulosa cell tumors suggests that these tumors exhibit intratumoral genetic heterogeneity. Future studies using targeted deep sequencing at the TERT promoter would elucidate whether TERT mutations are present at low frequencies in primary tumors. It is notable that we found the TERT C228T promoter mutation in the adult granulosa cell tumor-derived cell line KGN. Similarly, addition of TERT expression was required for immortalization of the SVOG cell line that was derived from primary granulosa cells, suggesting the need for telomerase activity in adult granulosa cell tumors. Previous studies have associated TERT promoter mutations with a worse prognosis in melanoma [40], glioblastoma, and bladder cancer patients [41]. In contrast, previous analysis of disease-specific survival in clear cell ovarian carcinoma comparing mutated TERT promoter and wild-type TERT promoter was not significant $(p=0.9592$, log-rank test) [12]. Although in our analysis there was a trend of worse disease-specific survival for TERT C228T mutant primary adult granulosa cell tumors, it was not significant ( $p=$ $0.0754, \log$-rank test). Additional studies investigating all TERT promoter mutations, including the less common ones C250T, C242T, and C243T [42], would be required to accurately compare the prognosis of TERT promoter mutant and wild-type adult granulosa cell tumor patients.

Overall, we found that TERT C228T promoter mutation was most common in adult granulosa cell tumors among ovarian carcinomas and sex cord-stromal tumors. Our data confirm the activation of telomerase in adult granulosa cell tumors via TERT C228T promoter mutation, although alternative telomerase activation methods in adult granulosa cell tumors may exist. Our results suggest that TERT 
activation may play a role in adult granulosa cell tumor recurrence. As such, telomere biology may be important for the progression of adult granulosa cell tumors.

Acknowledgements We thank all the women who generously donated the samples used in this study. This work is supported by the Terry Fox Research Institute Program Project grant \#1021, the British Columbia Cancer Foundation, Vancouver General Hospital - University of British Columbia Hospital Foundation (to the OvCaRe ovarian cancer research team, Vancouver) and Cancer Research UK (C17199/A18246). JAP is supported by the University of British Columbia Four-Year Doctoral Fellowship. We are grateful for the clinicians from each institution for patient recruitment. We thank the pathologists, Drs. C. Blake Gilks, Friedrich Kommoss, Ralf Buzow, Hugo M. Horlings, Anthony N. Karnezis, Hector Li Chang, Basile Tessier-Cloutier, and Lien Hoang, for reviewing slides. We also thank our technicians, Amy Lum and Janine Senz, for their advice.

\section{Compilance with ethical standards}

Conflict of interest The authors declare that they have no conflict of interest.

\section{References}

1. Akincilar SC, Unal B, Tergaonkar V. Reactivation of telomerase in cancer. Cell Mol Life Sci. 2016;73:659-1670.

2. Jafri MA, Ansari SA, Alqahtani MH, et al. Roles of telomeres and telomerase in cancer, and advances in telomerase-targeted therapies. Genome Med. 2016;8:69.

3. Zhang Q, Kim NK, Feigon J. Architecture of human telomerase RNA. Proc Natl Acad Sci USA. 2016;108:20325-32.

4. Chiba K, Johnson JZ, Vogan JM, et al. Cancer-associated TERT promoter mutations abrogate telomerase silencing. Elife. 2015;4:7918.

5. Kim NW, Piatyszek MA, Prowse KR, Harley CB, et al. Specific association of human telomerase activity with immortal cells and cancer. Science. 1994;266:2011-5.

6. Shay JW. Are short telomeres predictive of advanced cancer? Cancer Discov. 2013;3:1096-8.

7. Cesare AJ, Reddel RR. Alternative lengthening of telomeres: models, mechanisms and implications. Nat Rev Genet. 2010;11: 319-30.

8. Horn S, Figl A, Rachakonda PS, et al. TERT promoter mutations in familial and sporadic melanoma. Science. 2013;339:959.

9. Huang FW, Hodis E, Xu MJ, et al. Highly recurrent TERT promoter mutations in human melanoma. Science. 2013;339:957-9.

10. Vinagre J, Almeida A, Populo $\mathrm{H}$, et al. Frequency of TERT promoter mutations in human cancers. Nat Commun. 2013;4: 2185.

11. Huang FW, Bielski CM, Rinne ML, et al. TERT promoter mutations and monoallelic activation of TERT in cancer. Oncogenesis. 2015;4:e176.

12. Wu RC, Ayhan A, Maeda D, et al. Frequent somatic mutations of the telomerase reverse transcriptase promoter in ovarian clear cell carcinoma but not in other major types of gynaecological malignancy. J Pathol. 2014;232:473-81.

13. McConechy MK, Farkkila A, Horlings HM, et al. Molecularly defined adult granulosa cell tumor of the ovary: the clinical phenotype. J Natl Cancer Inst. 2016;108:djw134.

14. Wang YK, Bashashati A, Anglesio MS, et al. Genomic consequences of aberrant DNA repair mechanisms stratify ovarian cancer histotypes. Nat Genet. 2017;49:856-65.
15. Livak KJ, Schmittgen TD. Analysis of relative gene expression data using real-time quantitative PCR and the $2-\Delta \Delta C T$ method. Methods. 2001;25:402-8.

16. Lin TT, Letsolo BT, Jones RE, et al. Telomere dysfunction and fusion during the progression of chronic lymphocytic leukemia: evidence for a telomere crisis. Blood. 2010;116: 1899-907.

17. Roger L, Jones RE, Heppel NH, et al. Extensive telomere erosion in the initiation of colorectal adenomas and its association with chromosomal instability. J Natl Cancer Inst. 2013;105: 1202-11.

18. Flynn RL, Cox KE, Jeitany M, et al. Alternative lengthening of telomeres renders cancer cells hypersensitive to ATR inhibitors. Science. 2015;347:273.

19. Heaphy CM, de Wilde RF, Jiao Y. et al. Altered telomeres in tumors with ATRX and DAXX mutations. Science. 2011;333:425

20. Shain AH, Yeh I, Kovalyshyn I, et al. The genetic evolution of melanoma from precursor lesions. N Engl J Med. 2015;373: 1926-36.

21. Nault JC, Mallet M, Pilati $C$, et al. High frequency of telomerase reversetranscriptase promoter somatic mutations in hepatocellular carcinoma and preneoplastic lesions. Nat Commun. 2013;4:2218

22. Cheng L, Davidson DD, Wang $\mathrm{M}$, et al. Telomerase reverse transcriptase (TERT) promoter mutation analysis of benign, malignant and reactive urothelial lesions reveals a subpopulation of inverted papilloma with immortalizing genetic change. Histopathology. 2016;69:107-13.

23. Fuller PJ, Leung D, Chu S. Genetics and genomics of ovarian sex cord-stromal tumors. Clin Genet. 2017;91:285-91.

24. Rosario R, Cohen PA, Shelling AN. The role of FOXL2 in the pathogenesis of adult ovarian granulosa cell tumours. Gynecol Oncol. 2014;133:382-7.

25. Shah SP, Köbel M, Senz J, et al. Mutation of FOXL2 in granulosa-cell tumors of the ovary. N Engl J Med. 2009;360: 2719-29.

26. Kim MS, Hur SY, Yoo NJ, et al. Mutational analysis of FOXL2 codon 134 in granulosa cell tumour of ovary and other human cancers. J Pathol. 2010;221:147-52.

27. Kim T, Sung CO, Song SY, et al. FOXL2 mutation in granulosacell tumours of the ovary. Histopathology. 2010;56:408-10.

28. Jamieson S, Butzow R, Andersson N, et al. The FOXL2 C134W mutation is characteristic of adult granulosa cell tumors of the ovary. Mod Pathol. 2010;23:1477-85.

29. Schrader KA, Gorbatcheva B, Senz J, et al. The specificity of the FOXL2 c.402 C $>\mathrm{G}$ somatic mutation: a survey of solid tumors. PLoS ONE. 2009;4:e7988.

30. Al-Agha OM, Huwait HF, Chow C, et al. FOXL2 is a sensitive and specific marker for sex cord-stromal tumors of the ovary. Am J Surg Pathol. 2011;35:484-94.

31. Kobel M, Gilks CB, Huntsman DG. Adult-type granulosa cell tumors and FOXL2 mutation. Cancer Res. 2009;69:9160-2.

32. Leung DT, Fuller PJ, Chu S. Impact of FOXL2 mutations on signaling in ovarian granulosa cell tumors. Int $\mathrm{J}$ Biochem Cell Biol. 2016;72:51-54.

33. Jamieson S, Fuller PJ. Molecular pathogenesis of granulosa cell tumors of the ovary. Endocr Rev. 2012;33:109-44.

34. Liu JP, Li H. Telomerase in the ovary. Reproduction. 2010;140: 215-22.

35. Russo V, Berardinelli P, Martelli A, et al. Expression of telomerase reverse transcriptase subunit (TERT) and telomere sizing in pig ovarian follicles. J Histochem Cytochem. 2006;54:443-55.

36. Yamagata $\mathrm{Y}$, Nakamura $\mathrm{Y}$, Umayahara $\mathrm{K}$, et al. Changes in telomerase activity in experimentally induced atretic follicles of immature rats. Endocr J. 2002;49:589-95. 
37. Kossowska-Tomaszczuk K, De Geyter C, De Geyter M, et al. The multipotency of luteinizing granulosa cells collected from mature ovarian follicles. Stem Cells. 2009;27:210-9.

38. Lavranos TC, Mathis JM, Latham SE, Kalionis B, et al. Evidence for ovarian granulosa stem cells: telomerase activity and localization of the telomerase ribonucleic acid component in bovine ovarian follicles. Biol Reprod. 1999;2:358-66.

39. Chiba K, Lorbeer FK, Shain AH, et al. Mutations in the promoter of the telomerasegene TERT contribute to tumorigenesis by a twostep mechanism. Science. 2017;6358:1416-20.
40. Nagore E, Heidenreich B, Rachakonda S, et al. TERT promoter mutations in melanoma survival. Int $\mathrm{J}$ Cancer. 2016;139: $75-84$.

41. Killela PJ, Reitman ZJ, Jiao Y, et al. TERT promoter mutations occur frequently in gliomas and a subset of tumors derived from cells with low rates of self-renewal. Proc Natl Acad Sci USA. 2013;110:6021-6.

42. Scott GA, Laughlin TS, Rothberg PG. Mutations of the TERT promoter are common in basal cell carcinoma and squamous cell carcinoma. Mod Pathol. 2014;27:516-23.

\section{Affiliations}

Jessica A. Pilsworth ${ }^{1,2} \cdot$ Dawn R. Cochrane ${ }^{2}$ Zhouchunyang Xia ${ }^{2,3} \cdot$ Geraldine Aubert $^{4}$ - Anniina E. M. Färkkilä5,6 Hugo M. Horlings $\mathrm{s}^{2,3} \cdot$ Satoshi Yanagida ${ }^{7}$ Winnie Yang ${ }^{2}$. Jamie L. P. Lim $^{2} \cdot$ Yi Kan Wang $^{2} \cdot$ Ali Bashashati ${ }^{2}$. Jacqueline Keul ${ }^{8} \cdot$ Adele Wong $^{9} \cdot$ Kevin Norris $^{10}$ - Sara Y. Brucker ${ }^{8}$. Florin-Andrei Taran ${ }^{8} \cdot$ Bernhard Krämer $^{8}$. Annette Staebler ${ }^{11} \cdot$ Hannah van Meurs ${ }^{12} \cdot$ Esther Oliva $^{9} \cdot$ Sohrab P. Shah $\mathbb{1}^{2,13} \cdot$ Stefan Kommoss ${ }^{8}$. Friedrich Kommoss ${ }^{14}$. C. Blake Gilks ${ }^{3}$ Duncan M. Baird ${ }^{10}$ - David G. Huntsman ${ }^{2,3}$

1 Department of Medical Genetics, University of British Columbia, Vancouver, BC, Canada

2 Department of Molecular Oncology, British Columbia Cancer Agency, Vancouver, BC, Canada

3 Department of Pathology and Laboratory Medicine, University of British Columbia, Vancouver, BC, Canada

4 Terry Fox Laboratory, British Columbia Cancer Agency, Vancouver, BC, Canada

5 Children's Hospital and Department of Obstetrics and Gynecology, University of Helsinki and Helsinki University Hospital, Helsinki, Finland

6 Department of Radiation Oncology, Harvard Medical School, Dana-Farber Cancer Institute, Boston, MA, USA

7 Department of Obstetrics and Gynecology, The Jikei University School of Medicine, Tokyo, Japan
8 Department of Women's Health, Tübingen University Hospital, Tübingen, Germany

9 Department of Pathology, Massachusetts General Hospital, Boston, MA, USA

10 Division of Cancer and Genetics, School of Medicine, Cardiff University, Cardiff, UK

11 Tübingen University Hospital, Institute of Pathology, Tübingen, Germany

12 Department of Gynecology, Center for Gynecologic Oncology Amsterdam, Academic Medical Center, 1100 DD Amsterdam, The Netherlands

13 Department of Computer Science, University of British Columbia, Vancouver, BC, Canada

14 Institute of Pathology, Campus Bodensee, Friedrichshafen, Germany 